Etnográfica

Revista do Centro em Rede de Investigação em

Antropologia

vol. $18(2) \mid 2014$

Vol. $18(2)$

\title{
Da antropologia à antropologia aplicada ou a afirmação da disciplina no Norte de Portugal
}

From anthropology to applied anthropology or the affirmation of the discipline in Northern Portugal

\section{Xerardo Pereiro}

\section{(2) OpenEdition}

Journals

Edição electrónica

URL: https://journals.openedition.org/etnografica/3776

DOI: $10.4000 /$ etnografica. 3776

ISSN: 2182-2891

\section{Editora}

Centro em Rede de Investigação em Antropologia

Edição impressa

Data de publição: 1 junho 2014

Paginação: 425-440

ISSN: 0873-6561

\section{Refêrencia eletrónica}

Xerardo Pereiro, «Da antropologia à antropologia aplicada ou a afırmação da disciplina no Norte de Portugal», Etnográfica [Online], vol. 18 (2) | 2014, posto online no dia 09 julho 2014, consultado o 10 fevereiro 2022. URL: http://journals.openedition.org/etnografica/3776 ; DOI: https://doi.org/10.4000/ etnografica.3776

\section{(c) (i) (8)}

Etnográfica is licensed under a Creative Commons Attribution-NonCommercial 4.0 International License. 


\section{Da antropologia à antropologia aplicada ou a afirmação da disciplina no Norte de Portugal}

\section{Xerardo Pereiro}

A diferença entre antropólogos e outros profissionais da ciência está menos no seu objeto de estudo e método do que no seu lugar no processo económico de produção. A partir desta perspetiva - uma economia política da ciência - pretendo refletir sobre o processo de expansão e afirmação da antropologia (aplicada e implicada) no Norte de Portugal, desde finais da década de 1990. Para isso proponho uma reflexão sobre a minha própria experiência biográfica, abordando os casos da Universidade Fernando Pessoa (UFP) e da Universidade de Trás-os-Montes e Alto Douro (UTAD), numa ótica de análise da institucionalização da antropologia no Norte de Portugal, quanto à docência, investigação e intervenção. O texto ilustra como diferentes processos institucionais conduzem ao desenvolvimento de diferentes antropologias, a uma maior ou menor centralidade da sua oferta académica e a diferentes papéis sociais públicos.

PALAVRAS-CHAVE: antropologia aplicada, ensino superior, Norte de Portugal, UFP, UTAD.

From anthropology to applied anthropology or the affirmation of the discipline in Northern Portugal - The difference between anthropologists and other science professional's lies less in its subject matter and method than in its place in the economic process of production. From this perspecive - a political economy of science -, I want to reflect on the process of expansion and assertion of anthropology (applied and implied) in Northern Portugal, from the late 1990s. I propose a reflection on my own biographical experience, covering cases from the University Fernando Pessoa (UFP) and the University of Trás-os-Montes and Alto Douro (UTAD). My perspective is that of the institutionalization of anthropology in Northern Portugal, regarding teaching, research and intervention. The text illustrates how different institutional processes lead to the development of different anthropologies, to a greater or lesser centrality of the academic offer and different public and social roles.

KEYWORDS: applied anthropology, higher education, Northern Portugal, UFP, UTAD.

PEREIRO, Xerardo (xperez@utad.pt) - Centro de Estudos Transdisciplinares para o Desenvolvimento (Cetrad), Universidade de Trás-os-Montes e Alto Douro (UTAD), Portugal. 
“... o contexto local deve se transformar num laboratório a ser explorado, considerando-se seus problemas e história: é dele que deve emergir a 'vocação' pretendida pelo curso, onde colaboram docentes e discentes" (Tavares 2010: 59).

Na década de 1990 em Portugal, assiste-se à abertura de licenciaturas e unidades curriculares de antropologia em muitas instituições do ensino superior fora dos centros universitários de Lisboa e Coimbra, espaços centrais da prática antropológica portuguesa. ${ }^{1}$ Por um lado, este processo é favorecido pelo crescimento económico derivado da entrada de Portugal na antiga CEE (Comunidade Económica Europeia) e, por outro, pelo aumento do número de antropólogos formados na academia portuguesa e noutros países e respetiva integração profissional em instituições de ensino e investigação do país.

Esta expansão e o seu crescimento associado foram desenvolvidos, nalguns casos no Norte de Portugal, sob a noção de antropologia aplicada (Pereiro e Mendes 2005), como forma de diferenciação social de uma antropologia interventiva nos assuntos e problemas públicos. Estou a referir-me aos casos da Universidade Fernando Pessoa e da Universidade de Trás-os-Montes e Alto Douro; a primeira, uma universidade privada sediada no Porto (litoral) e a segunda, uma universidade pública sediada no interior norte (em Vila Real, com polos em Chaves e Miranda do Douro).

Embora não exista um consenso sobre a noção de antropologia aplicada (cf. Foster 1969; Bastide 1972; Van Willigen 1986; Eddy e Partridge 1987; Chambers 1985; Stull e Schensul 1987; Guerrero 1997; Ervin 2000; Goldman 2000; Podolefsky e Brown 2001; Tommasoli 2003; Pereiro e Mendes 2005; Olivier de Sardan 2005), podemos defini-la a partir do exercício antropológico de aplicação de dados, perspetivas, teorias e métodos para identificar, avaliar e contribuir para a resolução de problemas socioculturais. Ela corresponde a uma antropologia em ação, à prática de uma investigação-ação ou uma ação -investigação, não desenvolvida propriamente para uma instituição académica - universitária -, mas para organizações sociais não académicas (por exemplo, empresas, governos, administrações públicas, ONGD, associações, etc.).

No texto que se segue analiso algumas formas de produzir antropólogos profissionais (Guedes 2004) e a institucionalização da antropologia aplicada na Universidade Fernando Pessoa e na Universidade de Trás-os-Montes e Alto Douro, e assinalo casos vivenciados por mim através da minha carreira docente e de investigação nessas duas instituições de ensino superior. Pelo caráter limitado deste texto e refletindo a minha própria vivência, o espaço dedicado à

I Este trabalho é resultado da "Bolsa de licença sabática SFRH/BSAB/1186/2011" da Fundação para a Ciência e a Tecnologia (FCT) de Portugal. Também se enquadra no Cetrad (ver < www.cetrad. info >), centro de investigação financiado por fundos nacionais através da FCT, no âmbito do projeto PEst-OE/SADG/UI401 1/2011. Agradeço aos revisores, a Catarina Mira (CRIA) e ao colega Humberto Martins (UTAD) a revisão, comentários e sugestões para a melhoria deste texto. 
experiência da UTAD será mais alargado. Depois de analisar estes dois casos, apresento uma leitura pessoal da situação atual da antropologia no ensino superior do Norte de Portugal; finalmente esboço umas conclusões que assinalam as diversidades nos processos de reprodução social do conhecimento antropológico e da sua institucionalização universitária. Por questões de falta de espaço neste texto e também de menor conhecimento meu, não vou abordar outros casos como os da Universidade Aberta (campus do Porto) ou da Universidade do Minho, organizações nas quais houve uma institucionalização relativamente importante da antropologia.

\section{A ANTROPOLOGIA NA UNIVERSIDADE FERNANDO PESSOA}

Em 1990 foi criado (Portaria n. ${ }^{\circ}$ 909/90, de 27 de setembro), no Instituto Erasmus de Ensino Superior, o curso de antropologia, sendo posteriormente integrado como licenciatura na Universidade Fernando Pessoa (UFP), fundada através da fusão, em 1994-95, desse Instituto com o ex-Instituto Superior de Ciências da Informação e da Empresa (ISCIE), cujo interesse público foi reconhecido oficialmente pelo Ministério da Educação em 1996 (Decreto-Lei n. ${ }^{\circ} 107 / 96$, de 31 de julho). O curso funcionou quase durante uma década e o último ano em que foram admitidos alunos na licenciatura em Antropologia da UFP foi em 1998-99. O curso foi reestruturado em 2001, sem chegar a entrar em vigor, e suspenso em 2003-2004, devido ao decréscimo na entrada de alunos, o que podemos observar no quadro 1, comparativo sobre os candidatos aos cursos de antropologia em Portugal.

O curso de licenciatura da UFP foi o primeiro curso de Antropologia em Portugal a dar mais importância à dimensão aplicada da disciplina. Em 2003 foi criado o mestrado em antropologia (não abrindo, todavia), e, na mesma altura, abriu o curso de pós-graduação em intervenção humanitária, dirigido por Paulo Castro Seixas e ligado à sua experiência de investigação em Timor e na direção da ONGD Médicos do Mundo (delegação do Porto). Esta última formação, que posteriormente se converteu num mestrado, representou uma reinvenção da antropologia pelo caminho das suas aplicabilidades e da sua articulação e diálogo interdisciplinar com outras ciências sociais como a sociologia e não só.

Os antropólogos que protagonizaram este projeto foram, entre outros, Paulo Castro Seixas, Paula Mota Santos, Álvaro Campelo, Alcinda Cabral e Daniel Seabra. Todos eles, com exceção de Daniel Seabra (ex-aluno do curso de antropologia da UFP), tinham uma formação antropológica internacional (em Espanha, França e Reino Unido). A minha participação no projeto da UFP iniciou-se em meados dos anos 1990, colaborando na sua revista Antropológicas, e no ano escolar de 1997-98 fui docente de Antropologia Urbana no $4 .^{\circ}$ ano da licenciatura em Antropologia. Importa relembrar que este projeto significou uma tentativa de construir um núcleo antropológico diferenciado no 
Quadro 1

Candidatos aos cursos de Antropologia em Portugal (1998-2003)

$\begin{array}{lcccccc} & \text { FCT/UC } & \text { FCSH/UNL } & \text { ISCTE } & \text { ISCSP/UTL } & \text { UFP } & \text { UTAD } \\ 1998-1999 & 238 & 308 & 504 & 1073 & 10 & 5 \\ 1999-2000 & 298 & 206 & 606 & 980 & 0 & 7 \\ 2000-2001 & 215 & 1124 & 418 & 803 & 0 & 133 \\ 2001-2002 & 197 & 419 & 329 & 491 & 0 & 140 \\ \text { 2002-2003 } & 357 & 468 & 300 & 483 & 0 & 184 \\ 2003-2004 & - & - & - & - & - & - \\ 2004-2005 & 179 & 282 & 215 & 208 & 0 & 85 \\ 2005-2006 & 114 & 227 & 159 & 154 & 0 & 36\end{array}$

Legenda: FCT/UC - Faculdade de Ciências e Tecnologia da Universidade de Coimbra; FCSH/UNL - Faculdade de Ciências Sociais e Humanas da Universidade Nova de Lisboa; ISCTE - Instituto Superior de Ciências do Trabalho e da Empresa (que em 2009 adotou a designação Instituto Universitário de Lisboa - ISCTE-IUL); ISCSP/UTL Instituto Superior de Ciências Sociais e Políticas da Universidade Técnica de Lisboa (atualmente Universidade de Lisboa); UFP - Universidade Fernando Pessoa; UTAD - Universidade de Trás-os-Montes e Alto Douro. Fonte: Direção-Geral do Ensino Superior (<http://www.dges.mctes.pt $>$ ) e Relatório da Comissão Externa de Antropologia (síntese global consultada em < http://www.fup.pt/old/docs/ca/rsg_c2a4_antrop.pdf $>$, última consulta em maio de 2014).

país em relação à hegemonia científica dos centros antropológicos de Lisboa (ISCTE, FCSH-UNL e ISCSP). Como parceiros deste projeto estavam as Edições Fernando Pessoa e, parcialmente, a SPAE (Sociedade Portuguesa de Antropologia e Etnologia), símbolo de uma tradição antropológica nortenha muito ligada à arqueologia.

Uma outra etapa do processo foi a criação do Centro de Estudos em Antropologia Aplicada (CEAA) em 1999, avaliado na altura pela Fundação para a Ciência e a Tecnologia com a classificação de "Bom". A implementação do centro pressupunha a afirmação de uma investigação antropológica ligada a uma antropologia administrativa (Spradley e McCurdy 1980 [1975]), a uma antropologia para o desenvolvimento (Carmo 1999; Giménez Romero et al. 1999; Escobar 2000) e a uma antropologia em ação (Van Willigen 1986; Greenwood 2002). As linhas principais de trabalho do centro foram as do património cultural e desenvolvimento, museus, ajuda humanitária, cooperação para o desenvolvimento, urbanismo e planificação urbana, associativismo e organizações locais de desenvolvimento. O CEAA fechou em 2007 e passou a Centro de Estudos Culturais, da Linguagem e do Comportamento (Ceclico), tendo perdido a sua natureza disciplinar e passado a pluridisciplinar.

Alguns exemplos do envolvimento da investigação da Universidade Fernando Pessoa foram os da sua cooperação com o Ecomuseu do Barroso, a ONGD Médicos do Mundo ou a candidatura a património imaterial da humanidade 
da cultura oral galaico-portuguesa. Estes exemplos mostram a ênfase interventiva e aplicativa de teorias, métodos e técnicas antropológicas nas problemáticas sociais contemporâneas. A sua ligação com a Galiza e as suas instituições de cariz antropológico (por exemplo, departamentos universitários de antropologia, a Associação Galega de Antropologia, o Museu do Povo Galego, etc.) são outro dos traços distintivos deste projeto de institucionalização de uma antropologia aplicada a Norte.

Um outro importante papel público da antropologia da UFP foi o da intensa dinâmica de organização de congressos de antropologia; por exemplo, o VI Congresso Internacional de Estudantes de Antropologia (celebrado em 1998 e pela primeira vez de âmbito ibérico), o seminário "Cultura e Arquitetura" (celebrado em 1997), e as jornadas sobre exclusão e racismo (em 1997). Porém, este papel público não evitou que as "razões do mercado" servissem para motivar a suspensão da licenciatura em Antropologia da UFP. Coincidindo com um período de recessão económica de Portugal, que se arrasta até hoje, os interessados em estudar antropologia optaram por procurar universidades públicas, como podemos comprovar no quadro acima apresentado.

Contudo, e apesar desta situação, os antropólogos da UFP reinventaram a antropologia e o seu exercício profissional universitário num processo de adaptação à nova situação; e criaram uma licenciatura em Estudos Culturais com maior atratividade de alunos e encaixaram-se nalguns mestrados com uma ênfase aplicada e interventiva, como o da formação em Intervenção Humanitária.

\section{A ANTROPOLOGIA APLICADA NO POLO DA UTAD EM MIRANDA DO DOURO}

Em outubro de 1998 entraram em funcionamento a licenciatura em Antropologia Aplicada ao Desenvolvimento e uma outra em Trabalho Social no polo da UTAD em Miranda do Douro, criado nesse mesmo ano. A criação deste polo correspondeu à política de expansão da UTAD em Trás-os-Montes e em particular no distrito de Bragança, saindo assim da sua sede central em Vila Real e complementando-se o polo de Chaves (fronteira com a Galiza) com um terceiro espaço de ensino superior na fronteira com Zamora (Castela e Leão). No mapa da figura 1 podemos ver a localização geográfica relativa dos três polos da UTAD.

Miranda do Douro era em finais da década de 1990 uma pequena cidade situada na fronteira com a região de Castela e Leão (Espanha), com pouco mais de 2500 habitantes. O projeto político de criação de um polo universitário neste concelho com cerca de 10.000 habitantes representou uma experiência e um ensaio de desenvolvimento comunitário local, no qual teve muita importância o uso social da antropologia e o papel dos antropólogos, como veremos a seguir.

A criação da licenciatura em Antropologia Aplicada ao Desenvolvimento foi feita por Despacho da Reitoria da UTAD n. ${ }^{\circ}$ 6553/97 (publicado no Diário 


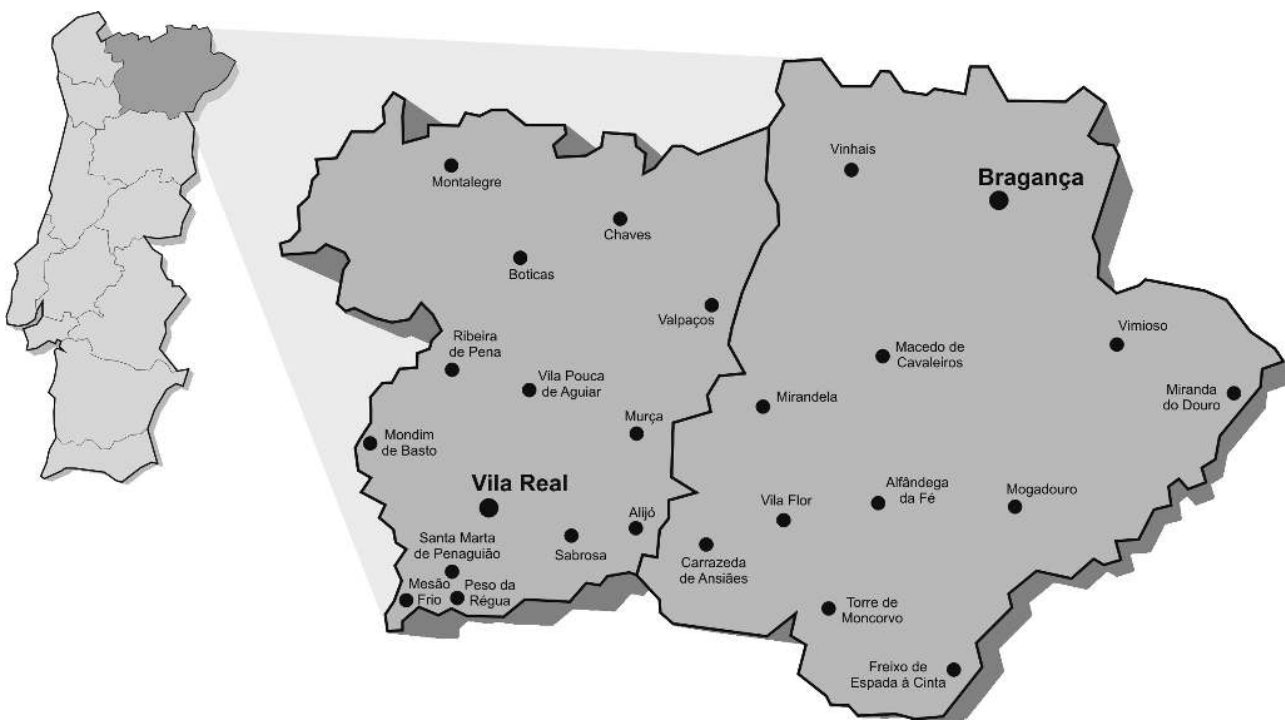

Figura 1 - Localização de Trás-os-Montes em Portugal e principais núcleos demográficos. (Fonte: Nicolau, 2011 1: 93)

da República, n. ${ }^{\circ}$ 195, 2. ${ }^{a}$ série, de 25 de agosto de 1997), tendo sido proposta pelo psicólogo José Vasconcelos Raposo, hoje professor catedrático de psicologia na UTAD, durante o mandato do reitor José Manuel Torres Pereira. Importa sublinhar que esta criação foi feita de forma paralela ao tradicional enquadramento departamental, gerando uma tensão conflitual com o Departamento de Economia e Sociologia da UTAD, o departamento por excelência das ciências sociais. Antes de 1997, a disciplina de antropologia era oferecida nalguns cursos da UTAD ligados à gestão agrária, sendo ministrada pela antropóloga Amélia Frazão Moreira, hoje professora da Universidade Nova de Lisboa.

Os primeiros anos da licenciatura em Antropologia foram marcados pelas difíceis e exigentes condições colocadas à entrada de alunos, o que levou a que nos dois primeiros anos tivéssemos poucos alunos de Antropologia (também comparativamente com Trabalho Social). A mudança nas condições de acesso dos alunos ao curso permitiu que no terceiro ano do projeto aumentasse a sua procura, com uma destacada feminização da demanda. $\mathrm{O}$ acréscimo da procura por parte de alunos permitiu a contratação e a construção de uma equipa de jovens antropólogos (Paulo Mendes, Pedro Silva, Octávio Sacramento, Luzia Oca, Humberto Martins, Xerardo Pereiro), com formação internacional em Portugal, Espanha, Reino Unido e Itália.

Com destaque para a etiqueta de "antropologia aplicada", e com o polémico epíteto de "desenvolvimento" associado, a construção da especificidade do curso pela sua aplicabilidade e intervenção social contribuiu para o aumento 
da diversidade da antropologia portuguesa, colocando-a não apenas no plano da análise e interpretação cultural, mas também no plano da reflexão crítica e orientação da mudança sociocultural:

"Os estudantes de Antropologia Aplicada conhecerão e utilizarão as ferramentas de investigação etnográfica, mas também aplicarão estas no desenho, execução e avaliação de projetos de desenvolvimento e outros (a título de exemplo, em áreas tão díspares quanto Saúde e Ambiente, Turismo e Integração Social ou Museologia e Urbanismo)" [texto de divulgação do curso].

Contudo, durante os primeiros anos de existência do curso e do polo, existiram duas formas diferentes de entender a antropologia aplicada. Uma primeira, a do Prof. Dr. José Vasconcelos Raposo (mentor do curso), projetava a antropologia aplicada como oposta e separada da antropologia (dita académica), do ponto de vista teórico, metodológico e da sua intervenção sobre o mundo. Neste sentido, segundo o próprio, a luta pelo reconhecimento da antropologia aplicada significava uma rutura com as genealogias antropológicas convencionais, com vista à construção de uma outra nova. A segunda, abraçada pelo grupo de antropólogos acima citados, entendia a antropologia aplicada como estando intimamente ligada ao corpus teórico-metodológico e ao projeto humanístico da antropologia. Portanto, considerávamos a polaridade entre antropologia aplicada e antropologia académica como uma falsa dicotomia, reconhecendo também que toda a antropologia é implicada e aplicável na reflexão e construção de modos de viver humanos. Paralelamente, existia nos nossos debates permanentes uma forte preocupação ética com a intervenção da antropologia e com as saídas profissionais e a empregabilidade dos licenciados em Antropologia, para além da própria academia. Um exemplo que projeta este argumento pode ser reconhecido nas potenciais saídas profissionais para os licenciados em Antropologia Aplicada indicadas na divulgação oficial do curso da UTAD:

- agências de desenvolvimento;

- museus e ecomuseus;

- fundações culturais;

- entidades regionais de turismo;

- escolas secundárias;

- parques naturais;

- organizações associativas;

- câmaras municipais;

- corpo diplomático;

- centros de saúde e hospitais;

- organizações não governamentais; 
- organizações governamentais, sobretudo nas áreas de ação social e cooperação internacional;

- universidades públicas e privadas, universidades populares e sénior;

- empresas, inclusive gabinetes de arquitetura, consultores turísticos, etc.

As principais áreas de atuação e tipos de trabalho a serem desempenhados pelo licenciado em Antropologia Aplicada ao Desenvolvimento, tal como indicado também nos documentos de divulgação do curso da UTAD, seriam as seguintes:

- antropologia e gestão cultural;

- minorias étnicas e integração social;

- saúde;

- planificação urbana e desenvolvimento local;

- avaliação de necessidades;

- património cultural e turismo;

- ensino e educação em contextos formais, informais e não formais;

- antropologia visual;

- estudos de mercado e de mass media;

- publicidade;

- assessoria e consultoria;

- ambiente e ordenamento do território.

Depois de um período inicial de desenvolvimento do polo (1998-2002), Vasconcelos Raposo, pró-reitor no mesmo, foi substituído por Chris Gerry, catedrático de economia do desenvolvimento da UTAD. Este último liderou um processo de construção de um corpo docente qualificado, de reestruturação da oferta educativa, de integração dos docentes em departamentos e centros de investigação da UTAD, de internacionalização, e de envolvimento com a comunidade mirandesa e fronteiriça. Este envolvimento foi realizado através da construção de um relacionamento participativo com a comunidade local, que acabou por se apropriar da universidade como sua, algo que se produziu em breve tempo, graças a uma atitude antropológica de colaboração institucional e de procura de soluções para os problemas da região (por exemplo, o despovoamento e o envelhecimento).

Posto isto, importa dizer que no polo de Miranda do Douro formámos 130 alunos em Antropologia Aplicada ao Desenvolvimento e várias centenas de trabalhadores sociais com formação específica em áreas da antropologia (Pereiro 2002). No quadro 2 apresentamos alguns dados da evolução do número de formandos em Antropologia.

Como podemos ver no quadro 2 , depois de 2003-2004 verifica-se um decréscimo do número de alunos candidatos ao curso de Antropologia paralelamente 
Quadro 2

Evolução do número de alunos de Antropologia Aplicada no polo da UTAD em Miranda do Douro

$\begin{array}{cccc}\text { Ano } & \text { N. }^{\mathbf{o}} \text { de vagas } & \begin{array}{c}\mathbf{N}^{\mathbf{0}} \text { total } \\ \text { de candidatos }\end{array} & \begin{array}{c}\text { Nota média do último } \\ \text { colocado na } \mathbf{~}^{\mathbf{a}} \text { fase }\end{array} \\ 1998-1999 & 50 & 5 & 141,3 \\ 1999-2000 & 50 & 7 & 140,6 \\ 2000-2001 & 50 & 133 & 123,9 \\ 2001-2002 & 50 & 140 & 118,5 \\ 2002-2003 & 50 & 184 & 125,1 \\ 2003-2004 & 50 & 191 & 106,5 \\ 2004-2005 & 45 & 98 & 106,7 \\ 2005-2006 & 30 & 36 & 110,9\end{array}$

Fonte: UTAD e Direção-Geral do Ensino Superior (ver < http://www.dges.mctes.pt/DGES/pt/Estudantes/Acesso/Estatisticas/EstudosEstatisticas/Regime+Geral+ES+P\%C3\%BAblico.htm > última consulta em maio de 2014)

a uma drástica redução do número de entradas, que ocorre muito pelo aumento da oferta de vagas dos cursos de Antropologia sediados em Lisboa e Coimbra e pelo relativo carácter periférico do curso e do polo no contexto geográfico e do ensino superior em Portugal. Estes factos foram determinantes (mas não exclusivos) na decisão da UTAD de suspender o curso de Antropologia Aplicada ao Desenvolvimento e de transferir o curso de Trabalho Social (agora Serviço Social), com uma permanente boa entrada de alunos, para Vila Real. Além destes factos, questões de política universitária da UTAD e de política nacional da rede universitária favoreceram estas mudanças.

As estratégias de ensino-aprendizagem da antropologia no polo de Miranda do Douro, efetivamente de pequena dimensão, focaram-se: (a) no ensino personalizado e na antropologia em ação - trabalho de campo implicado e aplicado quase permanente dos alunos; (b) no contágio do exotismo da região e na inovação sobre a tradição; (c) no impacto positivo na comunidade local e transfronteiriça, através de protocolos, relações de cooperação e cumplicidade com organizações, nas quais estão incluídas câmaras municipais, museus, associações de vária índole e juntas de freguesia; (d) na internacionalização por meio do estabelecimento de mais de 30 acordos Sócrates-Erasmus com outras universidades (e.g. Universitat Rovira i Virgili, Universitat de Barcelona, Universidade de Santiago de Compostela, Universidade de Sevilha, Universidade de Valladolid e Euskal Herriko Universitatea, em Espanha; Universidade de Lodz, na Polónia; Università della Sapienza, em Itália); (e) no estabelecimento 
de protocolos como outros departamentos de antropologia (e.g. Universidade de Louisville, nos Estados Unidos); (f) em ligações e relações privilegiadas com todos os departamentos de antropologia portugueses: ISCTE, FCSH-UNL, ISCSP/UTL e FCT/UC; e (g) na organização de eventos e reuniões científicas, servindo de reforço e complemento da formação dos nossos estudantes, além do seu contributo para o intercâmbio científico, para a criação de redes e a concretização de um campus transfronteiriço e transnacional (e.g. VII Congresso Internacional de Estudantes de Antropologia, Jornadas de Antropologia Aplicada, Congresso Leituras Antropológicas de Trás-os-Montes, Cursos de Língua e Cultura Mirandesas, etc.).

No sentido que apontamos, na nossa relação com as outras universidades portuguesas e espanholas, a licenciatura em Antropologia Aplicada ao Desenvolvimento serviu como espelho para pensar criticamente o ensino da antropologia no ensino superior e algumas reestruturações e redefinições de cursos (por exemplo os da Universidade Nova de Lisboa e do Instituto Superior de Ciências Sociais e Políticas).

Do mesmo modo, é preciso assinalar a importância de alguma investigação antropológica focada sobre as problemáticas transfronteiriças, o desenvolvimento local, o património cultural e o turismo. Esta investigação foi reforçada através da colaboração com a Asociación Etnográfica Bajo Duero, de Zamora, e a sua revista $O$ Fiadeiro/El Filandar, que acabou por integrar publicações em espanhol, português e mirandês - segunda língua oficial de Portugal, ligada ao astur-leonês - e tendo uma coordenação hispano-lusa. Esta cooperação permitiu construir pontes intelectuais entre os dois lados da fronteira e entre discursos antropológicos, literários e folcloristas. Alguns destes projetos e exercícios de investigação antropológica estão detalhados no quadro 3.

Neste relato sobre a experiência de Miranda do Douro é de apontar ainda que a licenciatura em Antropologia Aplicada foi reestruturada em 2004-2005. No entanto, em 2006-2007 a abertura de novas vagas foi suspensa por decisão da reitoria da UTAD e o primeiro ano deixou de receber alunos; em 2009 o curso foi novamente reestruturado e adequado a Bolonha (ver Diário da República n. ${ }^{\circ}$ 134, 2. ${ }^{\mathrm{a}}$ série, 13 de Julho de 2010, Despacho da UTAD n. ${ }^{\circ} 11426 / 2010$, pp. 37701-37704). Embora não tenha ainda voltado a abrir vagas, é relevante o objetivo definido no artigo $3 .^{\circ}$ deste despacho, e que mostra que tipo de antropologia se pretende ensinar e qual o modo de usar a antropologia aplicada - seguindo basicamente as orientações da reestruturação anterior:

"O 1. ${ }^{\circ}$ ciclo em Antropologia Aplicada da UTAD visa formar antropólogos ministrando uma formação teórico-prática que se sedimente como base fundamental para futuros desempenhos profissionais, logo completada com uma formação especializada em mestrados e doutoramentos. A formação em Antropologia Aplicada tem como base os corpos teóricos da Antropolo- 
Quadro 3

Projetos de investigação realizados por docentes da licenciatura em Antropologia Aplicada ao Desenvolvimento

\begin{tabular}{|c|c|c|c|}
\hline Ano & Projeto & Apoios & Resultados \\
\hline 1998-1999 & $\begin{array}{l}\text { Avaliação dos impactos } \\
\text { socioculturais } \\
\text { do rio Ulla (Galiza) }\end{array}$ & $\begin{array}{l}\text { Câmara Municipal de Palas } \\
\text { de Rei (Lugo) e Centro } \\
\text { de Interpretação } \\
\text { da Comarca da Ulloa }\end{array}$ & $\begin{array}{l}\text { Relatório publicado } \\
\text { pela UTAD }\end{array}$ \\
\hline \multirow[t]{2}{*}{$2001-2002$} & $\begin{array}{l}\text { A cultura do vinho } \\
\text { no Douro internacional }\end{array}$ & $\begin{array}{l}\text { Museu da Terra } \\
\text { de Miranda }\end{array}$ & $\begin{array}{l}\text { Exposição no Museu } \\
\text { da Terra de Miranda durante } \\
\text { o mês de julho de } 2002 ; \\
\text { vídeo antropológico }\end{array}$ \\
\hline & $\begin{array}{l}\text { Assessoria relativa } \\
\text { ao Ecomuseu do Barroso } \\
\text { (Montalegre) }\end{array}$ & $\begin{array}{l}\text { Câmara Municipal } \\
\text { de Montalegre }\end{array}$ & $\begin{array}{l}\text { Exposição; } \\
\text { vídeos antropológicos }\end{array}$ \\
\hline \multirow{4}{*}{$2002-2003$} & $\begin{array}{l}\text { Assessoria relativa } \\
\text { ao Ecomuseu do Barroso } \\
\text { (Montalegre) }\end{array}$ & $\begin{array}{l}\text { Câmara Municipal } \\
\text { de Montalegre } \\
\text { - Ecomuseu do Barroso }\end{array}$ & Vídeos antropológicos \\
\hline & $\begin{array}{l}\text { Projeto Filandouro, } \\
\text { de estudo e criação de uma } \\
\text { rede e tecido associativo } \\
\text { da raia transmontano- } \\
\text {-zamorana }\end{array}$ & $\begin{array}{l}\text { Associação Etnográfica } \\
\text { Bajo Duero, Universidade } \\
\text { de Salamanca, Câmara } \\
\text { Municipal de Miranda } \\
\text { do Douro, Junta de Castilla } \\
\text { y León }\end{array}$ & Relatório \\
\hline & $\begin{array}{l}\text { Avaliação da oferta } \\
\text { gastronómica do Alto } \\
\text { Tâmega e Barroso }\end{array}$ & $\begin{array}{l}\text { Ecomuseu do Barroso } \\
\text { - polo da UTAD em Chaves }\end{array}$ & \\
\hline & $\begin{array}{l}\text { Vídeo sobre os impactos } \\
\text { socioculturais do naufrágio } \\
\text { do Prestige }\end{array}$ & $\begin{array}{l}\text { Associação Galega } \\
\text { de Antropologia }\end{array}$ & $\begin{array}{l}\text { Documentário } \\
\text { As Praias do Chapapote }\end{array}$ \\
\hline $2003-2004$ & $\begin{array}{l}\text { A situação da mulher na } \\
\text { Terra Fria transmontana }\end{array}$ & $\begin{array}{l}\text { Corane (associação de } \\
\text { desenvolvimento local) }\end{array}$ & $\begin{array}{l}\text { Relatório; } \\
\text { documentário visual }\end{array}$ \\
\hline $2004-2005$ & $\begin{array}{l}\text { Memória e património } \\
\text { cultural do contorno } \\
\text { do rio Fresno }\end{array}$ & $\begin{array}{l}\text { Câmara Municipal } \\
\text { de Miranda do Douro }\end{array}$ & $\begin{array}{l}\text { Centro de Interpretação; } \\
\text { publicações; documentário } \\
\text { antropológico }\end{array}$ \\
\hline
\end{tabular}

Fonte: UTAD e elaboração própria.

gia acumulados nos dois últimos séculos e as metodologias de investigação qualitativa e quantitativa em Ciências Sociais. Esta formação visa a aplicação do conhecimento antropológico em íntima colaboração com as populações e os grupos humanos com os quais o antropólogo trabalha (isto é, segundo uma lógica em que deve predominar uma gestão participada entre os diferentes saberes). 
Os estudantes desta licenciatura conhecerão e utilizarão as ferramentas de investigação etnográfica, mas também aplicarão estas no desenho, execução e avaliação de projetos de desenvolvimento e outros (a título de exemplo, em áreas tão díspares quanto Saúde e Ambiente, Turismo e Integração Social ou Museologia e Urbanismo). A formação proporcionada aos estudantes de antropologia aplicada e do desenvolvimento na UTAD está orientada para um desempenho profissional em diferentes contextos sociogeográficos: ocidentais, africanos, asiáticos e latino-americanos, zonas com as quais Portugal e a Península Ibérica mantêm uma ligação histórica particular."

O polo da UTAD em Miranda do Douro acabou finalmente por fechar no ano letivo de 2009-10, por decisão da reitoria, regida na altura pelo Prof. Dr. Armando Mascarenhas, sendo delegado do reitor em Miranda do Douro o Prof. Dr. Humberto Martins. A licenciatura em Antropologia foi suspensa, a licenciatura em Serviço Social foi deslocada para Vila Real, e os docentes foram, na sua maioria, trabalhar para a sede central da UTAD em Vila Real.

Queria sublinhar ainda algumas questões para compreender melhor este processo agónico, em muitos sentidos, para alunos, docentes, funcionários e comunidade mirandesa em geral. A primeira é a da própria antropologização do curso de Trabalho Social (agora Serviço Social) e de outros como o de Turismo e o de Animação Sociocultural - a funcionar em Chaves -, como melhor forma de reconstrução social da vida profissional dos antropólogos. A segunda questão a destacar é que a antropologia e os antropólogos da UTAD se confrontam com a necessidade de mostrar a utilidade social e educativa do ensino da antropologia para não antropólogos, desafio que teve um certo sucesso na relação com a afirmação da aplicabilidade da antropologia em diferentes contextos socioprofissionais, entre os quais se encontram os universitários. A terceira é a da fraqueza institucional da antropologia na UTAD, que se deve fundamentalmente: (1) a não apresentar um enquadramento institucional departamental durante os primeiros anos de funcionamento do curso e do polo de Miranda do Douro; (2) ao facto de o curso ter nascido sem ter em atenção a ligação com os departamentos de ciências socias da UTAD; (3) à não conclusão do doutoramento por parte de muitos docentes e à implicação de uma subordinação política do ponto de vista estatutário e jurídico; (4) à distância física, simbólica e política do polo de Miranda do Douro face ao centro político da UTAD em Vila Real, num quadro de relações políticas no qual a antropologia era vista como algo exótico e auxiliar, portanto prescindível. 


\section{CONCLUSÕES:}

\section{A SITUAÇÃO ATUAL DA ANTROPOLOGIA NO NORTE DE PORTUGAL}

Atualmente assistimos a uma reconversão neoliberal da universidade e dos seus objetivos, a que não é alheia a antropologia (Narotzky 2011) e com exemplos desta transformação apresentados acima. A linguagem dominante nas nossas universidades integra termos como gestão, clientes, utilidade, eficiência, produtividade, competitividade e outros. Isto leva a antropologia a um questionamento sobre a sua utilidade social e a um desafio crítico de adaptação e resistência face aos estereótipos de que a disciplina é objeto (Pina-Cabral 1998). Enquanto formação disciplinar de 1. ${ }^{\circ}$ ciclo, em termos quantitativos, a sua procura é a que se mostra no quadro 4.

Quadro 4

Candidatos aos cursos de licenciatura em Antropologia entre 2009 e 2011

\begin{tabular}{|c|c|c|c|c|c|c|}
\hline & \multicolumn{2}{|c|}{2009} & \multicolumn{2}{|c|}{2010} & \multicolumn{2}{|c|}{2011} \\
\hline & 1. ${ }^{a}$ fase & 2. ${ }^{\mathrm{a}}$ fase & 1. ${ }^{a}$ fase & 2. ${ }^{\mathrm{a}}$ fase & 1. ${ }^{\mathrm{a}}$ fase & 2. ${ }^{\mathrm{a}}$ fase \\
\hline FCSH/UNL & 289 & 99 & 262 & 116 & 272 & 107 \\
\hline FCT/UC & 181 & 34 & 201 & 89 & 232 & 46 \\
\hline ISCTE-IUL & 184 & 70 & 271 & 108 & 213 & 69 \\
\hline ISCSP/UTL & 168 & 94 & 176 & 82 & 148 & 109 \\
\hline $\begin{array}{c}\text { Total } \\
\text { em Portugal }\end{array}$ & 822 & 297 & 910 & 395 & 865 & 331 \\
\hline
\end{tabular}

Fonte: Direção-Geral do Ensino Superior (< http://www.dges.mctes.pt/DGES/pt/Estudantes/Acesso/ >, consultado em maio de 2014) e elaboração própria.

De acordo com o quadro 4, temos em 2011 um número de 1196 pessoas que se candidataram em Portugal para estudar num curso universitário de Antropologia, considerando a primeira e a segunda fases do concurso nacional. É um número bem menor que o da década de 1990, o que significa que a antropologia atrai menos e convence menos o mercado.

Neste quadro geral atual, verifica-se que o enquadramento institucional da antropologia no ensino superior público do Norte de Portugal apresenta uma falta de oferta de licenciaturas e mestrados em Antropologia, acontecendo o mesmo na vizinha Galiza. Os antropólogos académicos trabalham na UTAD, na Universidade do Minho, na Universidade Fernando Pessoa e na Universidade do Porto em número decrescente, seguindo esta ordem. Paralelamente, assiste-se também a uma inserção profissional de alguns antropólogos nos museus (como é o caso de Jean-Yves Durand no Museu da Terra de Miranda), 
na sociedade civil (por exemplo, Gonçalo Mota e Ivett Krezett na associação Aldeia ou Fernando Cruz na Agir), na cooperação internacional (por exemplo, Sónia Fernandes nos Médicos do Mundo) e noutros âmbitos profissionais.

No caso da UTAD, atualmente, nós os antropólogos estamos enquadrados no Departamento de Economia, Sociologia e Gestão (um departamento de ciências sociais) da Escola de Ciências Humanas e Sociais. Lecionamos antropologia em licenciaturas e mestrados em Serviço Social, Psicologia, Turismo, Animação Sociocultural, Enfermagem, Arquitetura Paisagista, divididos por Vila Real e pelo polo de Chaves. No contexto do $3 .^{\circ}$ ciclo (doutoramento), existiu na UTAD um doutoramento em Ciências Sociais pelo sistema de orientação tutorial, no qual a antropologia tinha um pequeno espaço, mas este foi transformado num doutoramento em Estudos do Desenvolvimento, com parte curricular.

Embora exista um processo de negociação com a Universidade do Minho para abertura de uma licenciatura conjunta em Antropologia Aplicada, em Braga e Vila Real, na verdade o panorama aponta para uma reabertura por parte da UTAD de um $1 .{ }^{\circ}$ ciclo em Antropologia Aplicada. O curso de $1 .{ }^{\circ}$ ciclo está adequado ao Processo de Bolonha (Despacho da UTAD n. ${ }^{\circ} 11426 / 2010$, Diário da República, 2. ${ }^{\mathrm{a}}$ série, n. ${ }^{\circ}$ 134, de 13 de julho de 2010), mas falta ainda a aprovação por parte dos órgãos competentes da UTAD e o reconhecimento por parte da A3ES (Agência de Acreditação e Avaliação do Ensino Superior) para que tal projeto seja uma realidade.

Relativamente à investigação antropológica feita na UTAD, esta enquadra-se no Cetrad (Centro de Estudos Transdisciplinares para o Desenvolvimento), um centro de investigação pluridisciplinar no qual os antropólogos trabalham com economistas, sociólogos, gestores, historiadores e outros cientistas sociais. Além disso, é preciso destacar que alguns antropólogos da UTAD estão integrados no CRIA (Centro em Rede de Investigação em Antropologia). Por isso, tendo hoje mais investigadores e docentes que em princípios dos anos 1990 , a antropologia feita no Norte de Portugal afronta vários desafios, nomeadamente: (a) a sua reinvenção no contexto universitário e o fortalecimento da oferta de ensino e investigação nos três níveis de ensino superior (licenciatura, mestrado e doutoramento); (b) o seu trabalho em rede com as instituições universitárias vizinhas, com destaque para as da Galiza, com as quais há relações históricas de cooperação; (c) o aumento do prestígio e reconhecimento do papel social da antropologia em tempos de "crise" e mudança social acelerada; (d) a construção de um projeto que ensine aos alunos os modos de usar a antropologia fora da academia (Marshall 2010).

As experiências descritas acima, num tom subjetivo e numa perspetiva biográfica e experiencial, podem ser úteis como instrumento de reflexão sobre a institucionalização da antropologia no país, e no Norte de Portugal em particular. Penso que a antropologia académica portuguesa é muito relevante para o país e para o mundo, devendo afirmar-se como um elo de ligação mais forte 
entre a universidade e a sociedade (cf. Fry, Ketteridge e Marshall 2010), o que lhe exige um papel ativo na resolução de problemas sociais. A antropologia serviria assim, nas suas implementações institucionais e educativas diversas, como um espaço de mediação pedagógica, de investigação e interpretação (Guerra, Sureda e Castells 2011) dos sistemas socioculturais.

A antropologia em Portugal é hoje uma disciplina que contribui para o alargamento do conhecimento das formas de humanidade e, nos seus diversos ensinamentos e institucionalizações, deve possibilitar maximizar as potencialidades e vocações das universidades e os seus ancoramentos locais, considerando estes como laboratórios antropológico-sociais. Como fazer isto? A meu ver, explorando a carga semântica e reflexiva da antropologia e fugindo de um certo romantismo inútil tal como Otávio Velho (1995) tem referido, e aceitando antropologias heterológicas e transnacionais que ensinem o ofício de ser antropólogo profissional. Neste sentido, a antropologia está melhor posicionada do que outras ciências sociais para entender a realidade social e ao mesmo tempo para nela intervir.

\section{BIBLIOGRAFIA}

BASTIDE, Roger, 1972, Antropología Aplicada. Buenos Aires, Amorrortu.

CARMO, Hermano, 1999, Desenvolvimento Comunitário. Lisboa, Universidade Aberta.

CHAMBERS, Erve, 1985, Applied Anthropology: A Practical Guide. Prospect Heights, IL, Waveland Press.

EDDY, Elizabeth M., e William L. PARTIDGE (orgs.), 1987, Applied Anthropology in America. Nova Iorque, Columbia University Press.

ERVIN, Alexander M., 2000, Applied Anthropology: Tools and Perspectives for Contemporary Practice. Boston, Allyn and Bacon.

ESCOBAR, Arturo, 2000, "El lugar de la naturaleza y la naturaleza del lugar: globalización o posdesarrollo”, em A. Viola (org.), Antropología del Desarrollo: Teorías y Estudios Etnográficos en América Latina. Barcelona, Paidós.

FOSTER, George, 1969, Applied Anthropology. Boston, Little, Brown and Company.

FRY, Heather, Steve KETTERIDGE, e Stephanie MARSHALl (orgs.), 2010, Mellorar a Práctica Académica: Un Manual para a Ensinanza e a Aprendizaxe no Ensino Superior. Vigo, Universidade de Vigo.

GIMÉneZ romero, Carlos, et al. (orgs.), 1999, Antropología Más Allá de la Academia: Actas do VIII Congreso de Antropología. Santiago de Compostela, FAAEE - Asociación Galega de Antropoloxía.

GOLDMAN, Laurence R. (org.), 2000, Social Impact Analysis: An Applied Anthropology Manual.

Oxford, Berg. 
GREENWOOD, Davydd J., 2002, "Aplicar o no aplicar: per què l'antropologia i les ciències socials no poden existir sense l'acció", em Revista d'Etnologia de Catalunya, 20: 6-11.

GUEDES, Simoni Lahud, 2004, "Produzir antropólogos: algumas reflexões", Ilha, 6 (1-2): 185-196.

GUERRA, Francisco J., Jaume SUREDA, e Margalida CASTELLS, 2011 , Interpretación del Patrimonio: Diseño de Programas de Ámbito Municipal. Barcelona, Universitat Oberta de Catalunya.

GUERrero, Patricio (org.), 1997, Antropología Aplicada. Quito, Ediciones Abya-Yala.

MARSHALL, Stephanie, 2010, "A supervisión de proxectos e teses de licenciatura", em H. Fry, S. Ketteridge e S. Marshall (orgs.), Mellorar a Práctica Académica: Un Manual para a Ensinanza e a Aprendizaxe no Ensino Superior. Vigo, Universidade de Vigo, 219-238.

NAROTZKY, Susana, 2011 , "Las antropologías hegemónicas y las antropologías del sur: el caso de España", Revista Andaluza de Antropología, 1, n. ${ }^{\circ}$ temático: Antropologías del Sur, disponível em: < http://www.revistaandaluzadeantropologia.org > (última consulta em maio de 2014).

NICOLAU, Lurdes, 201 1, Ciganos e Não Ciganos em Trás-os-Montes: Investigação de Um Impasse Inter-étnico. Vila Real, UTAD, tese de doutoramento.

OLIVIER DE SARDAN, Jean-Pierre, 2005, Anthropology and Development: Understanding Contemporary Social Change. Londres, Zed Books.

PEREIRO, Xerardo, 2002, “L'enseignement d'anthropologie appliquée à l’Université du Trás-os-Montes et de l'Alto Douro - UTAD, Miranda do Douro", Regards Pluridisciplinaires: Revue Annuelle du Groupe Anthropologie du Portugal, 8: 174-177.

PEREIRO, Xerardo, e Paulo MENDES (orgs.), 2005, Textos de Antropologia Aplicada. Miranda do Douro, UTAD.

PINA-CABRAL, João de, 1998, "A antropologia e a questão disciplinar", em Análise Social, XXXIII (149): 1081-1092.

PODOlEFSKY, Aaron, e Peter J. BROWN, 2001, Applying Cultural Anthropology: An Introductory Reader. Mountain View, CA, Mayfield Publishing Company.

SPRADley, J.P., e D.W. McCURdy (1980 [1975]), Anthropology: The Cultural Perspective. Nova Iorque, John Wiley and Sons.

STUlL, Donald D., e Jean J. SCHENSUl (orgs.), 1987, Collaborative Research and Social Change: Applied Anthropology in Action. Boulder, CO, e Londres, Westview Press.

TAVARES, Fátima, 2010, "De que antropologia(s) precisamos? Profissionalização e perspectivas do ensino", em F. Tavares, L. Guedes, C. Simoni e Caroso (orgs.), Experiências de Ensino e Prática em Antropologia no Brasil. Brasília, Universidade de Brasília e Associação Brasileira de Antropologia, 51-62.

TOMMASOli, Massimo, 2003, El Desarrollo Participativo: Análisis Sociales y Lógicas de Planificación. Madrid, IEPALA.

VAN WILligEN, John, 1986, Applied Anthropology: An Introduction. South Hadley, MA, Bergin and Garvey (2. ${ }^{\text {a }}$ edição revista: Westport, CT, Bergin and Garvey, 1993).

VELHO, Otávio, 1995, "Algumas considerações sobre o estado atual da antropologia no Brasil", Antropolítica, 1: 103-113. 